\title{
TRLs 5-7 Advanced Manufacturing Centres, Practical Model to Boost Technology Transfer in Manufacturing
}

\author{
Leonardo Sastoque Pinilla ${ }^{1, *}$, Raúl Llorente Rodríguez ${ }^{2}$, Nerea Toledo Gandarias ${ }^{3}{ }^{(0)}$, \\ Luis Norberto López de Lacalle ${ }^{1,4}$ and Mahboobeh Ramezani Farokhad ${ }^{5}$ \\ 1 Aeronautics Advanced Manufacturing Center CFAA, 48170 Zamudio, Spain \\ 2 ITP Aero, 48170 Zamudio, Spain \\ 3 Department of Communications Engineering, University of the Basque Country (UPV/EHU), 48013 Bilbao, \\ Spain \\ 4 Department of Mechanical Engineering, University of the Basque Country (UPV/EHU), 48013 Bilbao, Spain \\ 5 Fachhochschule Dortmund, University of Applied Sciences and Arts, D-44047 Dortmund, Germany \\ * Correspondence: edwarleonardo.sastoque@ehu.eus; Tel.: +34-688-678-483
}

Received: 17 June 2019; Accepted: 5 September 2019; Published: 6 September 2019

check for updates

\begin{abstract}
Establishing collaboration strategies with interdisciplinary networks in research is a crucial success factor for the companies in any sector, especially in manufacturing for aeronautics. In the aeronautical supply chain, Small and Medium-sized Enterprises (SMEs) lack of these types of alliances with universities and other research institutions, which could give them access to shared and specialized knowledge, may strictly limit those companies to learning from their own experience. One way to break this dynamic for industrial companies is to be an active part of research, development, and innovation centres. In this paper, a study to create new advanced manufacturing centres is presented, centres whose activities are focused on Technology Readiness Levels (TRL) 5-7. The approach is based on a project management methodology, and it is applied to the aeronautical sector in the Basque Country. An initial study of the international experience and state of the art in this type of facility, as well as an analysis of the current socioeconomic environment of the Basque Country are presented. A benchmark study was done to identify the key processes that this centre must promote for this initiative to succeed, or those areas of knowledge that can make or break the initiative. Finally, the results showed a definitive picture for establishing an advanced manufacturing centre in the Basque Country. This work lays both the foundations of knowledge in the sector and the difficulties noted, so it can serve as guidance for similar initiatives.
\end{abstract}

Keywords: advanced manufacturing research centre; manufacturing readiness level; technology transfer; project management; manufacturing industry; industrial park

\section{Introduction}

The aviation sector, even though it has always been distinguished by establishing highly demanding requirements on the design and manufacturing of its components, has always been just behind on some issues such as the organization of production and manufacturing, compared to other sectors such as automotive and car component making [1]. However, in design or engineering, the direct application of the developments achieved through Research and Development (R\&D) was and is the mark of the sector. The development of manufacturing technologies to meet these requirements and how it would place the company's competitiveness against other global competitors is crucial, because this sector is fully globalized [2]. The current situation that productivity matters is really a keystone to achieve the short-term goal of delivering new engines or airframes for the always-growing market demand. 
The competitiveness of a company can be derived through four factors [3] (Figure 1), and the technology plays a key role in creating and maintaining it. Considering that the term technology can be defined as "all the knowledge, products, processes, tools, methods, and systems used in the creation of goods or the provision of services" [4], its importance for business and competitiveness (competences such as the use of basic technologies, human resources processes, management processes and technology management processes [5]) has been empirically confirmed in several contexts and is now notoriously rising in emerging countries.

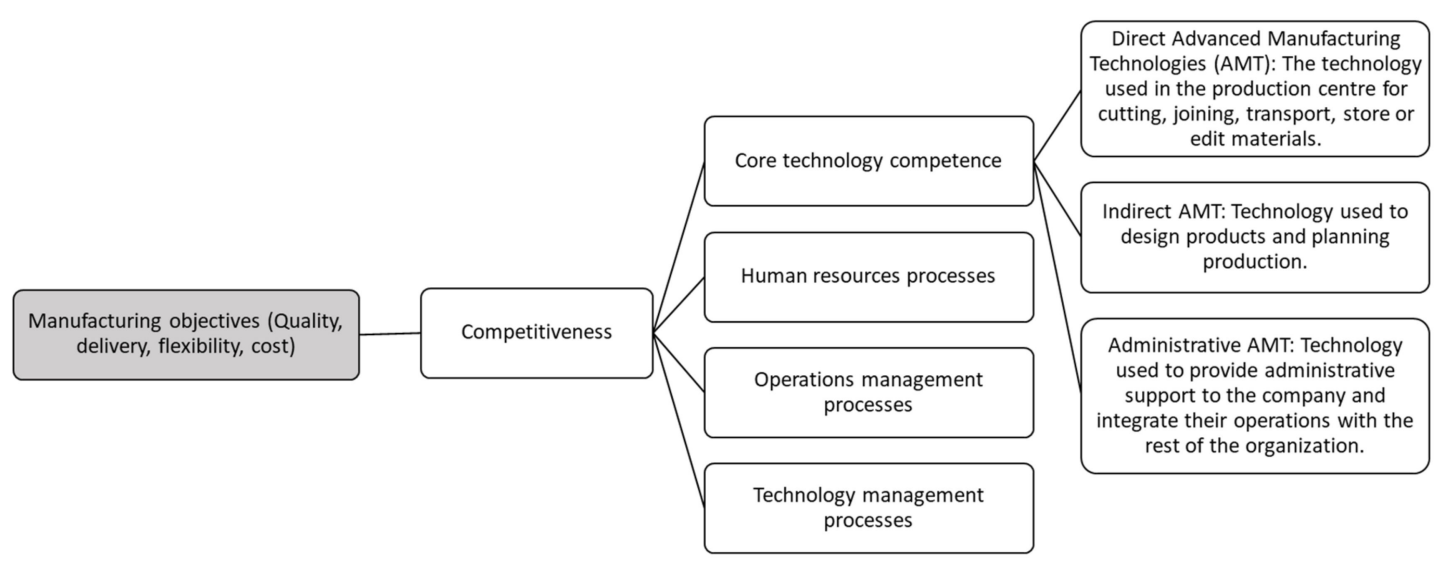

Figure 1. Conceptual network of competitiveness in the context of manufacturing.

Achieving dynamics in technological transfer about manufacturing is a demanding challenge in most companies [6]. The technology transfer process of the Basque Country in aeronautics was very high in the last decade, but it has some gaps, specifically the necessity of a place to try and test new technologies in an environment similar enough to that of the real production; this is the focus of working in the spot of manufacturing readiness level stages 5-7. There is need for a place to develop the technology to a maturity level (Technology Readiness Level (TRL) 7) and then quickly transfer the developments made by the technology agent networks, companies, and universities to the production needs of the companies. On the other hand, the collaboration of aeronautical Tier 1 and 2 companies with those providing production machines and solutions is key to accelerate any common development. Supply chain is a natural partnership for developing common projects of R\&D.

The vision of a conceptual "Advanced Manufacturing in Aeronautics Research Centre" (AMARC) is to establish a place, a location, a workshop, where the local governments, universities, and industrial partners meet and collaborate and dedicate their own resources to technology transfer activities defined by the members. In this new idea of AMARC, the concentration and specialization of key technologies, previously identified by companies and universities, are essential. Along with aeronautical companies, the centre must be composed of machine tool, systems, and accessories manufacturers (trying to avoid direct competition between them) creating real synergies that allow technology developments in representative conditions of the production plants. The development should be based on a temporal scope of collaboration between the partners that ensures cost effective project completion. Those partners must decide what activities should be developed, implemented, and monitored on an ongoing basis, including physical location of companies' technicians in the AMARC in stable project teams.

Related investigations in project management of advanced manufacturing research centres have focused on how to reduce the uncertainty of the acquisition/use of a technology through a suitable management plan and proper stakeholder management (managing stakeholders in early stages is critical to success) [7]. Uncertainty reduction issues also arise to mitigate risks in the early stages of the project. The economic and organizational form of the planning and funding is also referenced in numerous articles, as well as the relationship between the adoption of advanced manufacturing technologies and investment in infrastructure [8]. This leads us to consider the qualitative and quantitative factors that can help to predict whether the initiative will be successful or not, in order to 
prepare the necessary actions to reach project success [9]. Some researchers remarked on the importance of collaboration between the associates of the project in the creation of an Advanced Manufacturing Research Centre for the successful development of new technology, indicating that the companies involved must have a common language of business model, a similar corporate culture, and a proximity between the user and the producer [10,11].

Some other authors suggested that there is a correlation between organizational culture and the implementation of advanced manufacturing technology [12]. The benefits of advanced manufacturing and its results are closely related to the cultural characteristics of the companies involved (operational benefits, organizational satisfaction, and competitiveness) [13]. Research was carried out regarding how the socio-political regions affect the results obtained from the technology acquisition and the separation between the technology producers and the place where technological processes are made [14].

The aim of this paper is to perform an analysis of the current state of the technology transfer network and fulfil a benchmarking of reference models to identify and then study the key processes (stakeholder management, communication plan, risk management, and funding) leading to the success or failure of an AMARC. The results of this study will define the characteristics of the AMARC as a compendium of the work performed and adapted to the application object environment. To do so, a four-step context analysis should be performed. First, we show the Basque aerospace sector, studying the work done by the cluster, Hegan (Basque aerospace cluster). Second, it is necessary to understand the manufacturing technology concepts in the aerospace sector that will help to focus the lens and to bring together projects in the AMARC. Third, it is mandatory to analyse the current status of the network in the Basque technology agents and, finally, examine the levels of technology acquisition with an approach based on NASA's index Technology Readiness Level (TRL), when a technology is considered mature and capable of being industrialized.

\section{Background}

\subsection{The Basque Country Aerospace Sector}

The aerospace industry is prone to large, international consortia for research, product development, production, and operation due to the system complexity, high reliability demand, multi-domain characteristic, extremely long life cycles, valuable products, scale effects, and others [15]. According to the studies done by Hegan, the Basque aerospace cluster sector-leaving aside the airlines, ground handling, and airport service organizations-includes companies that are focused on engineering, manufacturing, and design that integrate the work of first level (Tier 1), e.g., large structures, engines, and complete subsystems; companies that carry out the integration of second level subsets (Tier 2), e.g., components, tool manufacturing, machining, heat and surface treatment; and research companies; institutes; and universities. In 2017, these companies' aggregate turnover and employment are $2425 \mathrm{M} €$ and 14,457 people, which represents $17.8 \%$ of the Spanish turnover and $25.5 \%$ of the Spanish aerospace employment. Moreover, the R\&D investment done by these companies represents $15.9 \%$ of the Spanish total $(201 \mathrm{M} €)$ [16]. Like any other sector, the challenges are struggling to maintain competitiveness, to improve effectiveness, and efficiency and to maintain their advantages in a sustainable way. The cluster has also set as one of its priority objectives the internationalization of its companies through a strong $R \& D$ investment necessary to maintain their position in the market [17].

There are also some inherent risks in the industry that can be summarized as the volatility of the geopolitical environment, managing the supply chain, competition in domestic and international markets, managing and retaining the talent [18], to name a few. The best way to carry on those risks is through establishing collaboration strategies that generate future innovation opportunities linked to expected incremental updates in order to improve product quality and productivity (better), reduce product costs (cheaper), and respond to market demands (faster). For the aerospace industry, these opportunities include improving the safety and environmental impact of aircraft [2]. Industry professionals and researchers have developed a key interest in how advanced manufacturing 
technologies can be used as a competitive tool in the global economy to combat the phenomenon of market fragmentation, product life cycle reduction, and increased demand for customization [19].

\subsection{Manufacturing Technologies in Aerospace}

"Advanced manufacturing technologies (AMT) involve manufacturing operations that create high-tech products using innovative techniques and new processes and technologies" [20]. This definition refers to the manufacture of high-technology products, processes, and solutions for future manufacturing and services. Many of these technologies are transverse, but the facilities to carry out these processes are not. There is also a wide variety of technologies but, in the case of the Basque market, they are focused on two large blocks aero-structures and motor-engines. The selection criteria of key technologies and technological strategies is one of the foundations of the successful creation of the AMARC. Figure 2 shows the relation between technological level and market impact.

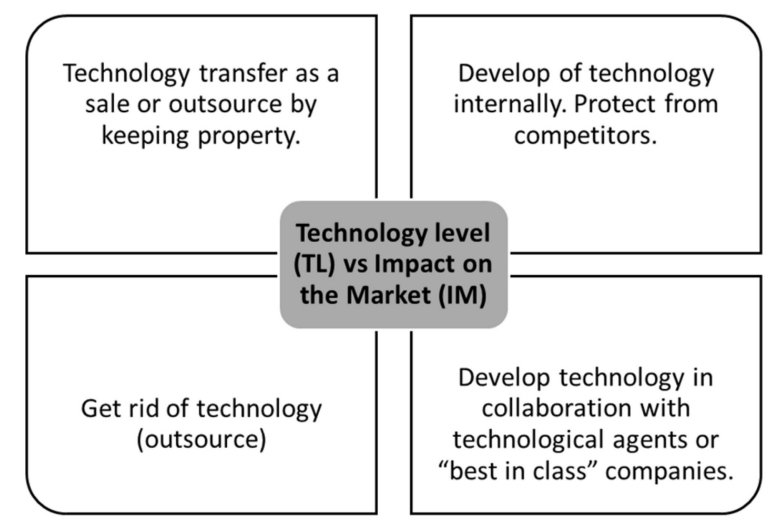

Figure 2. Technology level (TL) vs. impact on the market (IM).

AMARC activities should cover technologies that have greater impact on the market or higher technological competence. Furthermore, the results suggest that the company's technology strategy supports the development of both the network and technological skills [21]. The main objective should be the technological improvement and, therefore, the possible synergies between companies that participate in it.

\subsection{Actual Situation of the Technology Agents' Network in the Basque Country}

The technology agents' network in the Basque Country has some strengths in regard to applied research, such as:

- Network technology pioneer and leader state wide with high research capacity, driven by the history and importance of the industrial sector in the Basque Country.

- Solid public and private universities with a special relevance in engineering and sciences, basic pillars of manufacturing technologies. Faculty of Engineering of Bilbao is more than 100 years old.

- High levels of iterations with agents and European reference companies in the area of manufacturing, far above the rest of the country, through networking and collaborative projects.

- Clear support from Basque Country administrations, both in terms of investments and boosts to innovation forums and sectorial clusters, such as the Basque aerospace cluster.

- Strong iconic areas such as machine-tool manufacturing, capital goods, and automotive components and transportation, which have produced a strong pull.

However, some issues coming from industry demand for support remained unfilled. The same situation has been experienced in other countries with important academic tradition and large technology and industrial centres such as the UK, where there was a strong presence of technology centres with excellent capabilities, but that lacked a platform linking their developments and the 
industry needs. The lack was detected by the main Original Equipment Manufacturers (OEM) in the aeronautics world and by different government agencies, which prompted the creation of a centre covering these needs without duplicating what already exists in the field of basic or applied research. In the UK, the program was named Catapult.

\subsection{Levels of Technology Acquisition}

Introducing new technologies is an indicator of technological maturity in companies, and the Technology Readiness Level (TRL), designed by NASA in the late 1990s is a useful measure from an engineering/technical point of view (Table 1). The TRL index can be used as a rough estimation of the costs for conducting the required actions to reach the next TRL, time to market, risks taken, and uncertainty/lack of knowledge regarding the technology use/application and implications. While time-to-market shrinks with an increasing TRL, the costs within each step expand. A high TRL development within the aerospace sector demands large enterprises, workload, and infrastructure (for manufacturing and testing) and that cannot be achieved by universities.

Table 1. Technology acquisition process.

\begin{tabular}{ccc}
\hline Technology Readiness Level & Transference Process & Agents \\
\hline TRL 9-Complete industrialization & & Company \\
TRL 8-Optimization & & \\
TRL 7-Entry into production & Technology transfer & AMARC \\
TRL 6- Application development in product & Applied research & Technological Centres \\
TRL 5-Verification in production equipment & & Universities \\
TRL 4-Verification in representative prototype & Basic research & TR -Verification in the laboratory \\
TRL 2-Feasibility and profitability analysis &
\end{tabular}

AMARC-Advanced Manufacturing in Aeronautics Research Centre.

Two key factors shall also be considered: (a) The excellence at universities and technology centres to ensure a solid foundation of basic and applied research, and (b) an adequate transfer level between applied research and the results to industry, to avoid interference with the companies' production activity and to reduce the time and cost of transfer. TRL has been adapted by the manufacturing world as the MRL, in which M stands for manufacturing.

\section{Methodology}

A benchmarking based on a study of several documents and records can clear the path over how to assume a project of this nature, as well as the study of international references and the contextualization of this information to the Basque Country environment. In this case, it is composed of:

- Study of AMARC models created by aerospace companies in Europe and American countries that focus on the same technologies that has been identified as key for the Basque Country.

- Study of research focus of the AMARC identified before, their business models, and organizational plans.

- An analysis of technology, equipment capacities, and research capabilities, and a numerical evaluation of each characteristic according to this analysis (Table 2). 
Table 2. Equipment capacity vs. research capacity.

\begin{tabular}{|c|c|c|c|}
\hline Indicator & Description & Minimum & Maximum \\
\hline $\mathrm{CC}$ & $\begin{array}{l}\text { Scientific capacity: Scientific production in the last } \\
\text { three years (doctoral theses, publications, patents, } \\
\text { etc.) + staff size (doctors, researchers, etc.) }\end{array}$ & 0 & 4 \\
\hline VR & $\begin{array}{l}\text { Valuation of results: Direct or indirect assessment of } \\
\text { results of collaborative projects or technology } \\
\text { transfer in the last three years }\end{array}$ & 0 & 6 \\
\hline $\mathrm{CI}=\mathrm{CC}+\mathrm{VR}$ & $\begin{array}{l}\text { Research capacity: Global assessment of potential } \\
\text { capacity and results }\end{array}$ & 0 & 10 \\
\hline IE & $\begin{array}{l}\text { Equipment suitability (for processes and tests): } \\
\text { Technical quality of the equipment, similitude with } \\
\text { industrial environment, suitability of process ranges, } \\
\text { and useful working volume }\end{array}$ & 0 & 6 \\
\hline $\mathrm{DE}$ & $\begin{array}{l}\text { Availability of equipment: Term of response to } \\
\text { requests for use and compliance with schedules }\end{array}$ & 0 & 4 \\
\hline $\mathrm{CE}=\mathrm{IE}+\mathrm{DE}$ & $\begin{array}{l}\text { Capacity of equipment: Overall assessment of } \\
\text { suitability and availability }\end{array}$ & 0 & 10 \\
\hline
\end{tabular}

\section{Results and Discussion}

The public-private initiative can be key to the project's success, because the initial stages of a project of this type requires research, which means highly expensive and with a long time of specifications, where the commitment of public administrations can be an activating energy to projects of this type. The leverage effect of initial found can be obtained during the exploitation time of the AMARC.

Figure 3 shows the results of the evaluation based on the analysis of the recollected information to several centres in Europe with different configurations, carried out by the researchers. Here are compared (a) national university groups focused on applied research, (b) full integrated university groups focused on applied research with a relationship with companies based on specific projects, (c) national technological centres (without structural connection to the university), (d) university centres of applied research similar to the national university groups, but without the need to be financed by company contracts, and finally, (e) full integrated European centres, within the university (or very closely linked) with direct relation with the companies. Evidently each model depends on the national laws of the countries. However, in all the cases, those with more indexes involve universities in close ways, because university has a great advantage, bringing the training and young students together. Together with practical results regarding technology, key aspects such as industrial doctorate, training, lecturing in the last levels of degrees, and master science, connection of start-up entrepreneurship, etc. are the crux of the matter.

The benchmarking results indicate a similar position of the Basque technology agents, compared to the reference in Europe in areas such as advanced machining process, non-conventional processes, measuring techniques, simulation processes, systems integration, and process modelling in general for aircraft components. However, sometimes there is a dispersion of technological activity related to manufacturing and a redundancy of different agents investigating the same disciplines. The above causes are worsened by the lack of equipment and machinery with sufficient similarity to the industrial environment to provide the results in technology transfer projects. To reverse this situation, an investment effort is required. This is essential to develop a local network of excellence between technological agents and industrial companies (proper management of stakeholders).

As observed, there are several barriers related to transaction costs, coordination, management, and control of the activities of the various parties involved, which could inhibit the participation of companies in the investment share technology and R\&D [22]. The main trend of innovation policies in the last two decades is characterized by what is called "cooperative paradigm", or the promotion of co-operation between sectors-industry, government, and research-and between rival or vertically related companies [23]. Therefore, proper management of the information transmitted to 
potential partners during the creation of an AMARC is fundamental. Taking into account the impact of co-operation in private and social benefits, the biggest challenge for public policy is to find mechanisms that promote co-operation [24].

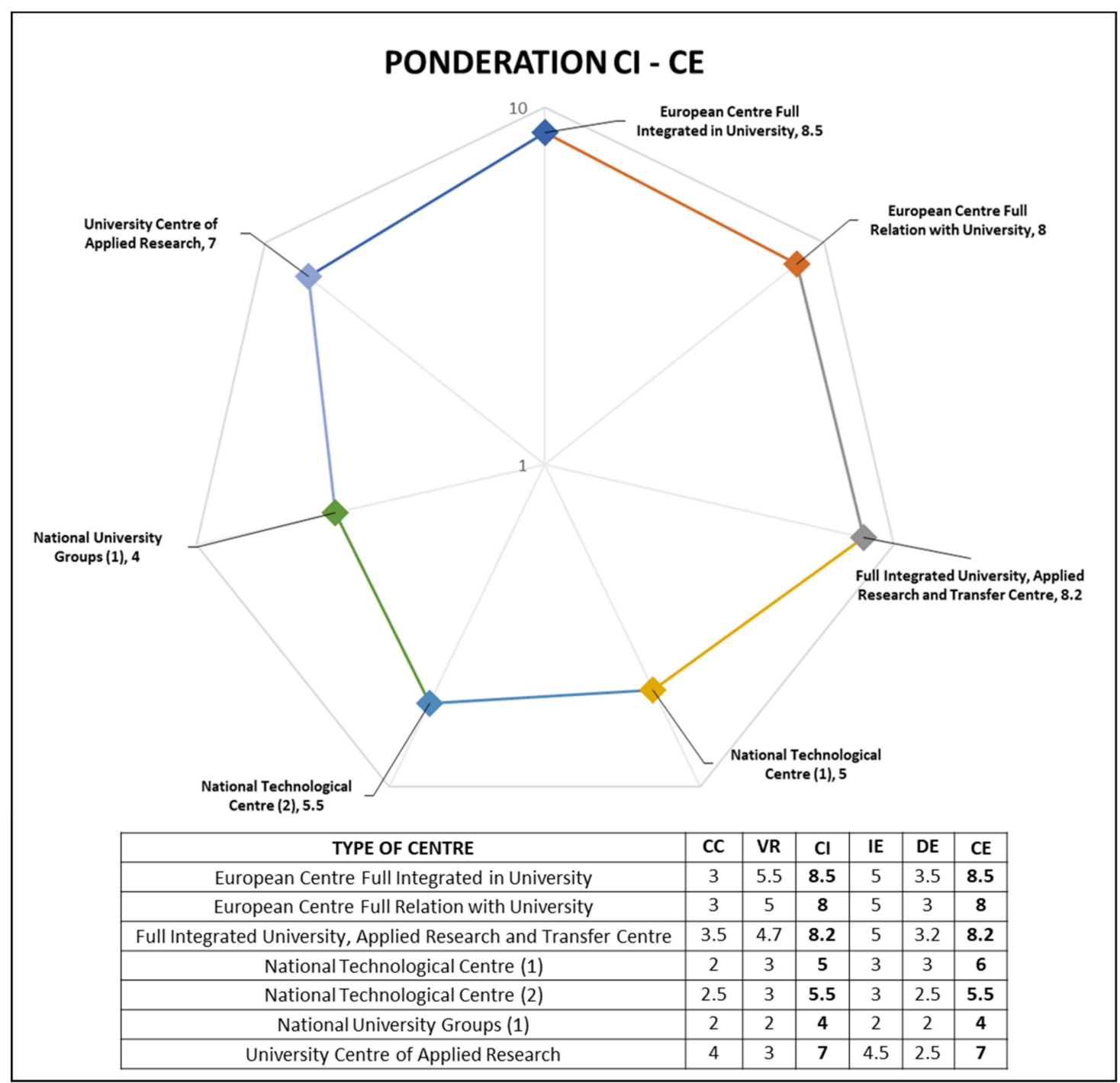

Figure 3. Results of the evaluation of CI (Research Capacity) and CE (Capacity of Equipment). Graph and data table.

Based on the collected information, it shall be considered that a cooperative model, in which several companies with common interests share risks and with the support of the supply chain, is the most appropriate and most likely to succeed management strategy of the AMARC project in the Basque Country. Consequently, the facilities must support the key technologies identified for the AMARC, advanced machining aerostructures, advanced processes for welding, and advanced machining aeroengines; facilities in which the industrial demonstration, launching, and acceleration of the initial production of new products can be successfully carried out. Furthermore, the reengineering process of existing products, the development of alternative manufacturing processes with the purpose of introducing qualitative leaps in profitability and the demonstration of the applicability of the developments of horizontal technologies shall be considered.

A proper risk management and planning must be conducted. Several studies have focused on evaluating the effectiveness and risks of $R \& D$ [25-27] and its influence on private efforts [28,29]. However, few studies have examined the criteria used by government assessors to assess these risks 
and projects [30,31]. It can be concluded that a centre with the aim of working around TRL 5-7 and involving public administrations, companies, and universities can help to increase the impact of applied research on final production lines, improving the general situation of the starting technological agent with respect to its former position in the international scenario.

\section{Application to the Basque Country Scenario-Establishment of the Advanced Manufacturing Centre for Aeronautics (CFAA, in Spanish)}

The new centre, CFAA, was inaugurated in 2017 in the Technological Park of Biscay, where several companies of the aeronautical and research sectors are located. The conception of this centre is a conjunction of initial ideas from the Basque Government (Dept. of Economic development and infrastructures), the University of the Basque Country (UPV/EHU) and the partnership for the Development of Advanced Aeronautics Manufacturing Techniques companies (more than 70 in 2019). The Basque Country Government and Provincial Council of Bizkaia were initial promoters and support the original idea, in collaboration with the Technological and Scientific Park of Bizkaia. CFAA enables the development and result transferring of research projects to production, without forgetting the generation, use, and fine-tuning of new knowledge in advanced manufacturing techniques [32]. Nowadays, the CFAA is formed by 78 partners, which has allowed to it complete several projects in different vital areas for the partners, and university. Twenty-five people form the staff of researchers, eight of whom are completing their $\mathrm{PhD}$ and seven, who are responsible for the project's coordination and research. It also has eight professors from the University who share their time in the centre's research. There are also 20 people from partner companies working in the centre and seven more are in dual training for partner companies. The combined nature of the technicians in the centre is one of the big strengths of the model.

In Table 3, the total number of companies in the partnership of companies is classified into type and sector. Types A, B, C have acquired a joint commitment to contribute to the centre through projects. Type D contributes in kind, giving tools or services to be used in the projects. As shown, several company sizes and sectors are involved, this is key because big companies have stronger R\&D means and culture than SMEs that can be shared trough the proper ways.

Table 3. Centre for Aeronautics (CFAA) partners summary (2019), classification by role and sector.

\begin{tabular}{ccc}
\hline Type & Industry & Quantity \\
\hline \multirow{2}{*}{ A } & Large-size machine tools & 1 \\
& Tier 1 aeroengines & 1 \\
\hline & Cutting-tool medium-size companies & 3 \\
B & Machine-tools medium-size companies & 1 \\
& Metrology companies & 2 \\
& Metrology and additive manufacturing & 1 \\
& Machine-tool small-size manufacturers & 1 \\
\hline & Additive m.-machine developers & 1 \\
& Cutting tools and accessories & 1 \\
& Digital transformation & 1 \\
& Engineering services & 1 \\
& Tier 2 aeroengines & 2 \\
& University & 1 \\
& Welding equipment and consumables & 2 \\
\hline
\end{tabular}


Table 3. Cont.

\begin{tabular}{ccc}
\hline Type & Industry & Quantity \\
\hline & Additive manufacturing-services & 1 \\
Cutting tools and accessories & 31 \\
Digital transformation & 5 \\
Engineering services & 4 \\
Technology providers & 1 \\
Work holding and fixtures & 5 \\
\hline Digital transformation & 1 \\
Engineering services & 4 \\
& Metrology equipment & 2 \\
& & 1 \\
\hline
\end{tabular}

\subsection{Daily Life Control_Project Time and Scheduling of Activities}

The activity of the CFAA is centred on the planning and realization of projects included in a List Of Projects (LOP), in which the intensive use of the resources is sought in fulfilment of the aims of the centre. This LOP is prepared on the basis of the proposals made by each of the members of the centre, sent for study and acceptance during a period of the year by a technical committee. The duration of the project depends on the planning agreed between the partner project lead and the centre, taking into account the availability of its resources, which is established according to the order of arrival of the requests, followed by the hierarchy of the partners. In general terms, three to six months is the project time, because longer projects usually tend to lose some practical view; as a matter of fact, longer projects are divided into shorter activities to be able to give companies tangible results. Figure 4 shows how many projects are proposed and led by the type of partners, Tier 1 or Tier 2 aeronautical companies are those pulling the rope; however, machine tool manufacturers are very active as well.

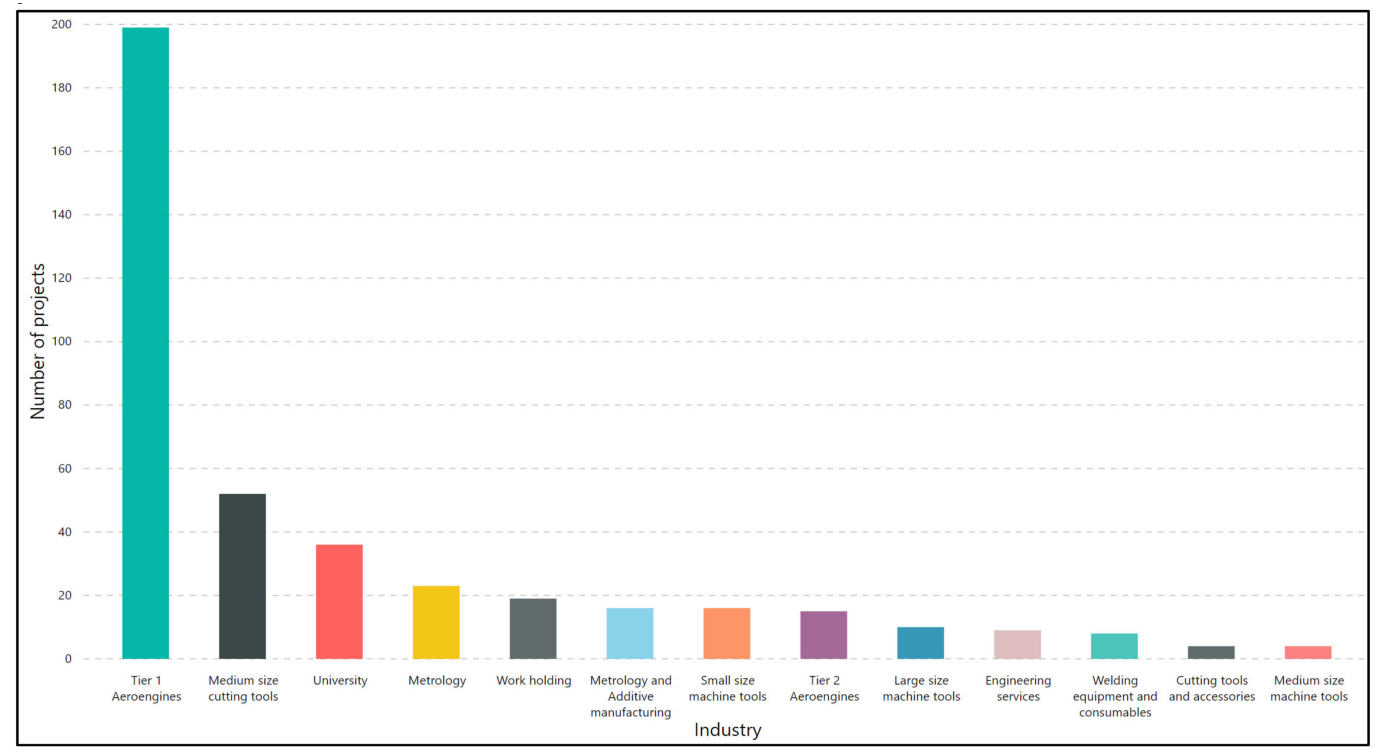

Figure 4. Project quantity resume by leader partner.

\subsection{Sharing of Costs}

As previously mentioned, the CFAA is the result of the support of several members. From that moment on, the financing of the activities and the acquisition of new resources has a mixed character. Initial funds provide by institutions were key to start the idea, and they had a real leverage effect on all launching activities in the foundation of the centre. 
The year-based budget of the CFAA will come from the payment income of the amounts for the realization of projects under the charge of the companies that make up the centre; the income of $R \& D$ projects in collaboration between the University of The Basque Country and company-partners, and several sporadic collaborations outside the company partnership, non-collaborative projects developed by the UPV/EHU through the CFAA; projects and additional contracts demanded by companies that make up the group (and those that do not); training activities and technical assistance carried out by the staff of the centre; other services that may arise from the operation of the centre (analysis services, rental of space for activities, reports elaborated by the CFAA, and so on); and the income arising from other donations, subsidies, or contributions to the CFAA.

\subsection{Property of Results and Data Gathering}

Due to the collaborative nature of the centre, different non-disclosure and confidentiality agreements have been established for the activities of the CFAA, as well as their projects and results. Therefore, the ownership of property and the exploitation rights over them will correspond to the partner (or partners) that have financed the respective activity or the research project (either a company of the partnership or the own UPV/EHU for its own activities or for other works or projects in collaboration). However, those results that could disqualify, due to their publication or diffusion, the recognition of Industrial or Intellectual Property rights should be considered as reserved matters and not diffusible, unless an agreement to do so is reached between the parties.

On the one hand, the CFAA must preserve the confidentiality of all information received from the companies, which complies with the general agreement of confidentiality that involves the staff of the CFAA or assigned to it. The information provided by each company belongs per se to the company of origin, namely blueprints or significant technical details of parts and components. All personnel present regularly in the CFAA must register and sign the Non-Disclosure Agreement (NDA), which links the centre and the partners if they so demand.

The network established around CFAA also allows a rapid use of new results in daily production, and in some cases has made easier to exploit new patents, as in the case of cryogenic cooling using $\mathrm{CO}_{2}$ (REF W02017/202622 A1). Anyway, some results are industrial secrets, to be use in daily production, so special care about information, pictures, and other issues must be kept in mind always.

\subsection{Manufacturing Execution System (MES) at CFAA}

The need to control the intensive use of the CFAA resources and respect the public-private nature of the information has established different tools developed by the centre, tending to create an "ad hoc" Manufacturing Executing System (MES) that allows acquisition data of the use of machines, record work time of staff, quality control, and finite programming of these resources, with the aim of making the audit of this information transparent, and on this basis, create not only horizontal, but also vertical control cycles. The data obtained from the different components of the system allows in turn to apply artificial intelligence techniques that facilitate the programming of the projects' tasks, the realization of the maintenance on the resources, and the creation of added value throughout the projects.

Graphical utilities were developed to manage the flow of projects and to define the load per machine, in addition to charge the costs per machine or technicians to each company account. As an example, Figure 5 shows the total number of hours invested by each group of resources in the development of the projects of CFAA from 2017 to 2019. 


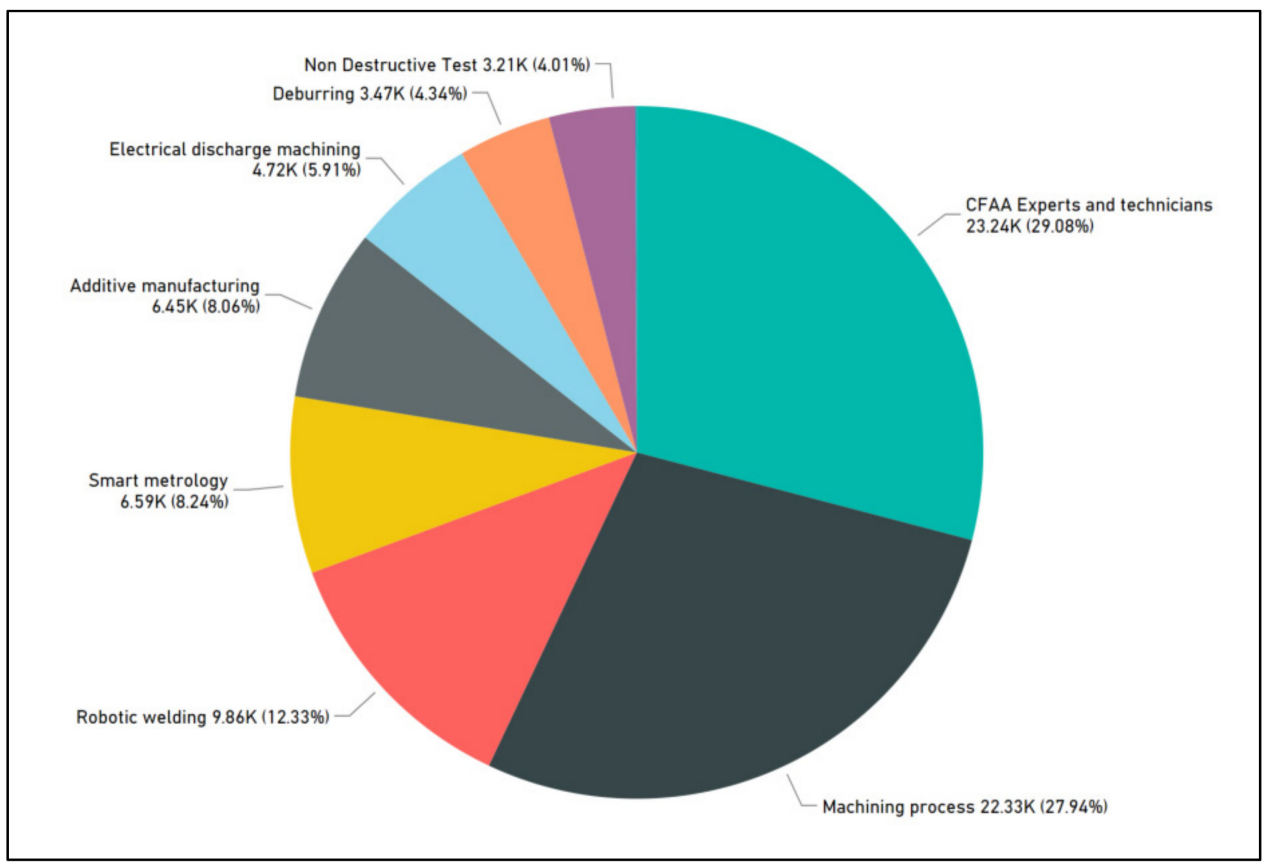

Figure 5. Executed hours and percentage of used resources in project execution 2017-2019.

\subsection{The Effect of the Location at a Technological Park}

The research type facilities of AMARC are welcome at technological parks because they are based on the presence of knowledge-based companies. For instance, around the University of Sheffield Advanced Manufacturing Research Centre (AMRC) a whole technological park has spread.

The Technological park of Bizkaia is one of the outstanding ones in Europe, close to the airport and surrounded by several companies which are partners of the CFAA. Taking advantage of the park's existence, the new centre was located here, with a high-tech surrounding in accordance with the aim of the centre.

Location is important in centres open to full collaborations. University faculties, vocational training schools, access by public transport are also important reason for the success of centres of this type.

\subsection{Sustainability}

Sustainability was undertaken in two lines, economic and environmentally. The economic performance of a centre of this sort must achieve the balance of incomes vs. costs in less than two years, taking into consideration that it is a non-profit research centre. Three scenarios can be presented, regarding budget evolution and term:

- Initial period. When costs can be slightly higher than incomes from companies' projects or by competitive calls. New models and systems always need some time to achieve their regular performance. The excess of incomes can equilibrate the initial shortfall during the following years.

- Budget balance. In the mid-term, balance must be achieved. The size of the AMARC must be escalated to this basic principle.

- Increase of incomes coming from projects. All money in excess of costs would be used for more people in the system, new doctoral grants, or new equipment. As an example, CFAA has increase a $21 \%$ in the three years since its inauguration.

Regarding environmental issues, a centre of this type does not make real production, however it must be an example of good practices. International Organization for Standardization (ISO) 14001:15 sets out the parameter for an environmental management system; it can be a global goal to achieve by the organization. 
Technology can help to reduce the manufacturing impact, that is why, at CFAA, a technique under research is cryogenic cooling using $\mathrm{CO}_{2}$ (second use of $\mathrm{CO}_{2}$ ). This technology reduces machining temperature and can eliminate emulsion coolants (water $+5-10 \%$ oil) in the same applications [33,34].

In Figure 6, some environmental good practices are shown, performed at CFAA. To the left, a container for oil disposal and stained paper, a chip removal system and a conveyor, metal powder for additive manufacturing, with particle size ranging from 10 to 20 micrometres. Last image is a detail of how powder is treated before being used. The CFAA waste and disposal system is around $7-11 \%$ of a real factory of the same layout and machines but at full production.

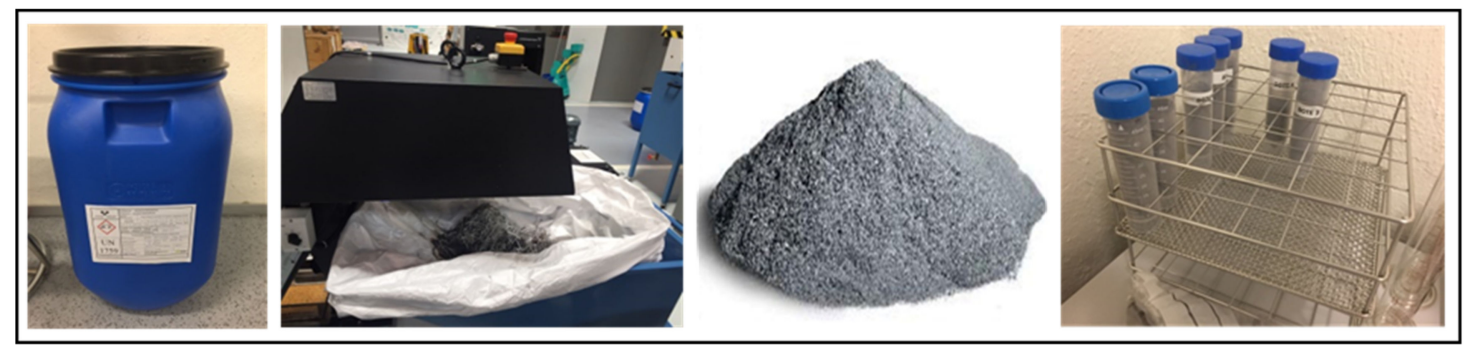

Figure 6. Harmful substance deposit, chip collecting system, metallic powder for additive manufacturing, and powder testing.

\section{Conclusions}

It can be concluded that in cases and industrial sector with structural deficit of certain knowledge and skills, an advanced manufacturing research centre could be a good solution. The aerospace sector, as a whole, is an intensive investment sector in R\&D and some others in the supply chain as well, as is the machine tool sector. However, most SMEs in the Basque Country do not have R\&D fixed structures for developing their own research activities. Important efforts are being made in upgrading student's qualifications through the specialization and improvement of the local universities and formation centres. They are also collaborating with the local companies to know the main flaws of the graduates. Moreover, there is an important network of technology centres in the Basque Country with the ability to work in the aerospace sector.

The ultimate goal of the AMARC concept should not be focused on centres dedicated to horizontal development of specific manufacturing technologies (machining or welding technologies), but on those dedicated to the totality of the manufacturing process, integrating development activities of pure process modelling tools, simulation, adaptive control flow of operations, automation, reaching a maturity level that allows the technology flow without risk of the developed productive portfolio of partner companies.

Industrial partners could assume technology acquisition activities with a high probability of success. The sharing of funding, both public and private, can improve the profit margin and the capacity of research and development with other partners, which would increase the chances of success. The critical mass created will allow participation in consortia in European or national projects under conditions of greater equality with the European centres of reference, and with the possibility of choosing to participate in activities with higher technological return and access to larger budgets. Small companies participating in centre would make an even greater leap, considering their investment limitations in R\&D and the difficulty for developing steady technology acquisition activities.

Machine-tool systems and tool manufacturers have better opportunities to sell their products to companies if development projects were successful previously at the AMARC, to gain access to better funding, to improve their proximity to end customers and to obtain benefits from access to technological excellence inside and outside the AMARC. This type of centre is also a showroom for machine tool assemblers and other technology providers.

After presenting the premises and antecedent, several conclusions can be pointed out: 
- $\quad$ Research centres around TRLs 5-7 must comprise several companies, universities, and strong support from public administrations.

- Collaboration of the supply chain with OEM or Tier 1 is highly recommend, having the new centre model as a vertical conception: Effort is focused on one particular industrial sector.

- The centre can boost the relative position of one research group in a university with applied research to leading positions.

- The initial list of machines and systems is key to achieve an intensive use of the centre means. Machines must be purchased considering a useful life of at least seven years.

- The location in a technological park with common services is a key aspect in the project. Common services, environment, and easy access by public transport is key.

- Management of the centre must be performed by a university or technological agent, all thinking in being an open centre to all partners and that the management of the centre is really on behalf of the full consortium.

Author Contributions: L.S.P. wrote the main ideas, R.L.R. developed the benchmarking, N.T.G. and M.R.F. helped with project management details, and L.N.L. described the key aspects of the CFAA.

Funding: We thanks the strong support to the centre of the Basque Government (Dept of Economic development and infrastructures and SPRI) and Council of the Province of Biscay, Technological park of Zamudio and University of the Basque Country. Special thanks to Eng. Alfredo Lopez-Diez for the ideas and daily efforts to develop the centre model along with ITP Aero, Danobat Group and the other 76 company partners. Thanks are due to Joserra Otegi from UPV/EHU and funds from Excellence groups of the Basque university system no. IT1337-19 (from Basque Government). Centre CFAA can be looked up at: https://www.ehu.eus/en/web/CFAA/home

Conflicts of Interest: The authors declare no conflicts of interest.

\section{References}

1. Gartner. Aerospace and Defense Context: 'Magic Quadrant for Manufacturing Execution Systems'. Available online: https://www.gartner.com/en/documents/3835363/aerospace-and-defense-context-magic-quadrantfor-manufac (accessed on 20 May 2019).

2. Murman, M.; Walton, M.; Rebentisch, E. Challenges in the Better, Faster, Cheaper Era of Aeronautical Design, Engineering and Manufacturing; The Lean Aerospace Initiative, RRP00-02; Massachusetts Institute of Technology: Cambridge, MA, USA, 2000.

3. Kak, A.; Sushil, H. Sustainable Competitive Advantage with Core Competence: A Review. Glob. J. Flex. Syst. Manag. 2002, 3, 23-38.

4. Information Resources Management Association. Technology Adoption and Social Issues: Concepts, Methodologies, Tools, and Applications; IGI Global: Hershey, PA, USA, 2018.

5. Banwet, D.K.; Momaya, K.; Shee, H.K. Competitiveness Through Technology Management: An Empirical Study of Indian Software Industry. Int. J. Serv. Technol. Manag. 2003, 4, 131-155. [CrossRef]

6. Selmi, N. The Difficulties of Achieving Technology Transfer: Issues of Absorptive Capacity; Communications of the IBIMA: Madrid, Spain, 2013; Volume 1.

7. Boyer, K.K.; Keong Leong, G.; Peter, T.; Lee, J.K. Unlocking the potential of advanced manufacturing technologies. J. Oper. Manag. 1997, 15, 331-347. [CrossRef]

8. Zheng, E.Z.H.; de Carvalho, M.M. Managing Uncertainty in Projects: A Review, Trends and Gaps; Gestão e Projetos, GeP: Clark, NJ, USA, 2016; Volume 7, pp. 95-109.

9. Su, C.S.; Shih, C.T.; Hsu, S.C. Forecasting the Success of Implementing Advanced Manufacturing Technology. Adv. Mater. Res. 2013, 774-776, 1393-1396. [CrossRef]

10. Gertler Meric, S. Being There: Proximity, Organization, and Culture in the Development and Adoption of Advanced Manufacturing Technologies. Econ. Geogr. 1995, 71, 1-26. [CrossRef]

11. Zammuto, R.F.; O'Connor, E.J. Gaining Advanced manufacturing Technologies' Benefits: The Roles of Organization Design and Culture. Acad. Manag. Rev. 1992, 17, 701-728.

12. Mc Dermott, C.; Gregory, N. Organizational culture and advanced manufacturing technology implementation. J. Oper. Manag. 1999, 17, 521-533. [CrossRef] 
13. Gao, Q.X.; Feng, Q.Q. Research on the organizational model and human resource management based on advanced manufacturing technology. In Proceedings of the IEEE International IE and EM Conference on Industrial Engineering and Engineering Management, Macau, China, 7-10 December 2010; pp. 577-581.

14. Gertler Meric, S. Implementing Advanced Manufacturing Technologies in Mature Industrial Regions: Towards a Social Model of Technology Production. Reg. Stud. 1993, 27, 665-680. [CrossRef]

15. Staack, I. Establishment of the Swedish Aeronautical Research Centre (SARC). Aircr. Eng. Aerosp. Technol. 2019, 91, 857-864. [CrossRef]

16. Hegan-Basque Aerospace Cluster. El Clúster de Aeronáutica e Industria Espacial Del País Vasco: Orígenes, Evolución y Trayectoria Competitiva. Available online: https://www.hegan.com/memoria2017/report2017.pdf (accessed on 20 May 2019).

17. Hegan-Basque Aerospace Cluster. Plan de I+D+i de HEGAN 2017-2020 (PIDiH1720). 2018. Available online: https://www.hegan.com/Corporativa/MostrarNoticia.aspx? C7yOogmVDdKxYedVvjnm9Q90785678d90785678d (accessed on 20 May 2019).

18. Ey.com. Top 10 Risks in Aerospace and Defense (A\&D)-EY. 2017. Available online: https://www.ey.com/ publication/vwluassets/ey-top-10-risks-in-aerospace-and-defense/\%24file/ey-top-10-risks-in-a\&d.pdf (accessed on 20 May 2019).

19. Hottenstein, M.P.; Casey, M.S. Facilitation of advanced manufacturing technology: Implementation and transfer. Ind. Manag. 1997, 39, 5.

20. Sallee, C.M.; Erin, A.; Rosaen, A. The University Research Corridor Support for Advanced Manufacturing in Michigan State University; University of Michigan: Ann Arbor, MI, USA; Wayne State University: Detroit, MI, USA, 2010.

21. Ritter, T.; Gemünden, G.H. The impact of a company's business strategy on its technological competence, network competence and innovation success. J. Bus. Res. 2004, 57, 548-556. [CrossRef]

22. Becker, W.; Dietz, J. R\&D cooperation and innovation activities of firms: Evidence for the German manufacturing industry. Res. Policy 2004, 33, 209-223.

23. Bozeman, B.; Sooho, L.; Gaughan, M.; Chompalov, I. The impact of research collaboration on scientific productivity. Soc. Stud. Sci. 2005, 35, 673-702.

24. Lim, S.; Kim, J. Technology Portfolio and Role of Public Research Institutions in Industry 4.0: A Case of South Korea. Appl. Sci. 2019, 9, 2632. [CrossRef]

25. Meyer-Krahmer, F.; Montigny, P. Evaluations of innovation programmes in selected European countries. Res. Policy 1989, 18, 313-332. [CrossRef]

26. Ormala, E. Nordic experiences of the evaluation of technical research and development. Res. Policy 1989, 18, 333-342. [CrossRef]

27. Roessner, J.D. Evaluating government innovation programs: Lessons from the U.S. experience. Res. Policy 1989, 18, 343-359. [CrossRef]

28. David Paul, A.; Bronwyn Hall, H. Heart of darkness: Modeling public-private funding interactions inside the R\&D black box. Res. Policy 2000, 29, 1165-1183.

29. Klette Jakob, T.; Moen, J.; Griliches, Z. Do subsidies to commercial R\&D reduce market failures? Microeconometric evaluation studies. Res. Policy 2000, 29, 471-495.

30. Hsu, D. Experienced entrepreneurial founders, organizational capital, and venture capital funding. Res. Policy 2007, 36, 722-741. [CrossRef]

31. Lee, M.; Om, K. Evaluation of national R\&D projects in Korea. Res. Policy 1996, 25, 805-818.

32. CFAA. Mission. 2017. Available online: https://www.ehu.eus/en/web/CFAA/eginkizuna (accessed on 20 May 2019).

33. Pereira, O.; Rodríguez, A.; Barreiro, J.; Fernández-Abia, A.I.; de Lacalle, L.N.L. Nozzle design for combined use of MQL and cryogenic gas in machining. Int. J. Precis. Eng. Manuf. Green Technol. 2017, 4, 87-95. [CrossRef]

34. Pereira, O.; Martín-Alfonso, J.E.; Rodríguez, A.; Calleja, A.; Fernández-Valdivielso, A.; López de Lacalle, L.N. Sustainability analysis of lubricant oils for minimum quantity lubrication based on their tribo-rheological performance. J. Clean. Prod. 2017, 164, 1419-1429. [CrossRef]

(C) 2019 by the authors. Licensee MDPI, Basel, Switzerland. This article is an open access article distributed under the terms and conditions of the Creative Commons Attribution (CC BY) license (http://creativecommons.org/licenses/by/4.0/). 